\title{
Effect of supplemental oxygen on development of retinopathy of prematurity
}

\author{
Porimal Kumar Das ${ }^{1 *}$, Mohammad Monir Hossain ${ }^{2}$, Mahfuza Shirin³, Md. Shamim Parvej Ibne \\ Halim $^{4}$, Shubhra Prakash Paul ${ }^{5}$, AHM Enayet Hossain ${ }^{6}$
}

\author{
${ }^{1}$ Assistant Registrar, Department of Paediatrics, Mugda Medical College Hospital, Mugda, Dhaka, BANGLADESH. \\ ${ }^{2}$ Professor, Department of Neonatal Medicine and NICU, BICH and Dhaka Shishu (Children) Hospital, Dhaka, BANGLADESH \\ ${ }^{3}$ Associate Professor, Department of Neonatal Medicine and NICU, BICH and Dhaka Shishu (Children) Hospital, Dhaka, BANGLADESH \\ 4Junior Consultant, Department of Paediatrics, Mugda Medical College Hospital, Mugda, Dhaka, BANGLADESH \\ ${ }^{5}$ Lecturer, Department of Community Medicine, Rajshahi Medical College, Rajshahi, BANGLADESH \\ ${ }^{6}$ Professor (Paediatric Ophthalmology), National Institute of Ophthalmology, Dhaka, BANGLADESH. \\ Email: poridas@yahoo.com
}

Abstract Background: Retinopathy of prematurity (ROP) which is also known as retrolental fibroplasia is a vasoproliferative disorder that affects premature infants. Despite of major advancement in management, it continues to be a leading cause of childhood blindness throughout the world. As there had been very few studies conducted here and very few information regarding this disease are available we conducted this study. Aim of the study: The aim of this study was to evaluate the effect of supplemental Oxygen on development of retinopathy of prematurity. Methods: This was a prospective cohort study which was conducted at the Special Care Baby Unit (SCABU) and Intensive Care Unit (ICU) of Dhaka Shishu (Children) Hospital, Dhaka, Bangladesh during the period from July 2012 to December 2014. In total One Hundred and Twenty (120) 0-28 day's old neonates of both sexes possibilities of ROP were finalized as the study population. Data were processed and analyzed using statistical software SPSS version 17, EPI info 7. Result: In this study, thirty (36.59\%) neonates got oxygen up to 72 hours did not developed ROP. Only one $1(2.63 \%)$ ROP $(+v e)$ neonates received oxygen for 73 to 120 hours. Those who received oxygen for duration of $170-218$ hours and $>218$ hours developed ROP, RR was 2.01 [1.17-3.48] and 4.67 [2.71-8.03] respectively and $(\mathrm{p}<0.05)$. On the other hand, five neonates $(13.16 \%)$ of ROP $(+v e)$ got percentage of oxygen in inhaled air (41-60)\% and this concentration was found statistically significant risk for ROP, RR 3.48 [2.61-4.64] but there was no risk associated with $\mathrm{FiO} 2(24-32) \%$ or 33-40\% in inhaled air. SpO2 (95-99) \% was present in $29(76.32 \%)$ of ROP (+ve) neonates and $19(23.17 \%)$ in ROP (-ve) neonates. Conclusion: The practice of providing oxygen and blood transfusion are often lifesaving, a more judicious approach to the use of such therapies may help to reduce the problem of ROP. Inappropriate supplementation of oxygen may not correct hypoxia or may lead to hyperoxia. Both the conditions are injurious to neonatal health. During oxygen therapy, $\mathrm{SpO}_{2}$ value and more precisely the $\mathrm{PaO}_{2}$ value on neonate should be maintained within a target range. The finding of this study should be explored in the future.

Key Words: Supplemental Oxygen, Retinopathy, Prematurity, ROP

*Address for Correspondence:

Dr. Porimal Kumar Das, Assistant Registrar, Department of Pediatrics, Mugda Medical College Hospital, Mugda, Dhaka, Bangladesh

Email: Email: poridas@yahoo.com

Received Date: 21/10/2019 Revised Date: 10/11/2019 Accepted Date: 26/12/2019

DOI: https://doi.org/10.26611/10141513

This work is licensed under a Creative Commons Attribution-NonCommercial 4.0 International License. (cc)) BY-NC

\begin{tabular}{|l|l|}
\hline \multicolumn{2}{|c|}{ Access this article online } \\
\hline Quick Response Code: & Website: \\
\cline { 1 - 1 } & www.medpulse.in \\
& \\
\hline
\end{tabular}

INTRODUCTION

Retinopathy of prematurity (ROP or retrolental fibroplasia as it was called previously) is a vasoproliferative disorder that affects premature infants. Despite major advances in management, it continues to be a leading cause of childhood blindness throughout the world. ${ }^{1}$ The spectrum of ROP ranging from mild, transient changes in the retina with progression to severe progressive vasoproliferation, scarring, detachment of retina and blindness. ${ }^{2}$ World Health Organization's Vision 2020 program has recognized Retinopathy of Prematurity (ROP) as an important cause of childhood blindness in industrialized 
and developing countries and Retinopathy of prematurity (ROP) is a major avoidable cause of blindness in children. ${ }^{3}$ Over $50 \quad 000$ children are probably blind worldwide from ROP. ${ }^{4}$ The 'first epidemic' of ROP took place in the 1940s and 1950s, affected larger premature infants, and was associated with unmonitored oxygen supplementation. ${ }^{5}$ Over the course of the following decades, supplemental oxygen was carefully titrated, and the 'second epidemic' affected extremely premature infants in highly developed countries who were receiving appropriate dosages of oxygen. ${ }^{6} \mathrm{With}$ the institution of carefully timed screening examinations and treatment with cryotherapy, panretinal photocoagulation and advanced surgical techniques, the rate of blindness from ROP has dropped substantially in developed countries. As developing countries began to adopt modern neonatology techniques in the 1980s and 1990s, increasing the survival of preterm neonates, ROP began to emerge in middleincome countries (the 'third epidemic'), where it can account for as much as $60 \%$ of childhood blindness. ${ }^{7}$ The second epidemic occurred in the 1970 s and $1980 \mathrm{~s}^{8,9}$ which was because of increased survival rate of very-low-birthweight infants. ${ }^{10}$ While the widespread implementation of vitamin A supplementation and measles immunization programs have led to a reduction in vitamin A deficiencyrelated blindness in many poor countries, retinopathy of prematurity is now undergoing a third wave of endemicity, particularly in newly industrializing countries in Latin America and Asia. ${ }^{11,12}$ In these countries, close oxygen monitoring is not always possible, and screening for ROP is not routine. The wide range of birth weights (BWs) and gestational ages (GAs) of babies with severe ROP in Latin America and large cities in Asia suggests that this epidemic combines features of the first and second epidemics. ${ }^{12-15,6 \text {, }}$ 5 Retinopathy of prematurity (ROP) occurs due to abnormal proliferation of retinal vessels. The most important risk factors which predispose to development of ROP include oxygen therapy, anemia needing blood transfusion, sepsis and apnea. ${ }^{16}$ In spite of extensive research and progress in the understanding of this disease in recent years, an explosive increase in severe ROP is seen in low-income countries. ${ }^{2}$ In the US and other industrialized nations $\mathrm{O}_{2}$ therapy for neonates was introduced in the 1930's and early 1940's. Its use then became widespread throughout the world. The use of oxygen was implemented in neonatal practice in the absence of any randomized studies. The dose was (and still is in some places) not measured well. Additionally, the newborn's oxygenation levels were not measured routinely until Arterial Blood Gases (ABG's), capillary samples, transcutaneous $\mathrm{PO}_{2} \quad\left(\mathrm{TcPO}_{2}\right)$ and, more recently, monitoring of oxygen saturation by pulse oximetry $\left(\mathrm{SpO}_{2}\right)$ became available. However, it is one of the drugs most frequently used in NICU's, many times without any limits or control. ${ }^{1}$ Oxygen was discovered more than 200 years ago and it has been administered to more infants in the world than any other neonatal treatment. However, we still do not fully know how much is wise to give or how much infants actually need in relation to variations in illness and gestational and postnatal age. But we have known for many years that "too much oxygen" damages the retina. ${ }^{1,17}$. Many neonatal units have adopted new oxygen saturation policies to reduce the amount of supplemental oxygen given to premature infants. Technological advances have allowed continuous monitoring of arterial oxygen saturation levels. The question today is "which among the factors related to hypercarbia, hyperoxia and significant and rapid oxygen fluctuation has a greater or lesser impact on ROP'? ${ }^{1}$ Oxygen is a drug and it is essential in some condition in Neonatal Intensive Care Unit. It should be administered in quantity that is absolutely necessary. Both hypoxia and hyperoxia are detrimental to the baby. ${ }^{18,19}$ Ophthalmological examination of preterm babies is not routinely done in Bangladesh, despite the common occurrence of multiple risk factors for ROP among hospitalized, preterm infants. ${ }^{21}$ As survival of preterm infants in low resource settings increases, ROP will be increasingly important as a potential cause of blindness, emphasizing the critical importance of ophthalmic examination in premature infants from as early as two weeks after birth, with urgent initiation of treatment when ROP is diagnosed. ${ }^{20-22}$ In Bangladesh study regarding use of supplemental oxygen and oxygen profile has been evaluated properly but scant data are available and there is no definite protocol of oxygen use in local neonatal intensive care units. So this study is undertaken to find out the effect of supplemental oxygen on development of ROP.

\section{OBJECTIVES}

\section{General objective:}

- To evaluate the effect of supplemental Oxygen on development of retinopathy of prematurity.

\section{Specific Objective:}

- To identify the $\mathrm{SpO}_{2}, \mathrm{PaO}_{2}, \quad \mathrm{FiO} 2$ levels responsible for ROP in preterm neonates.

\section{MATERIALS and METHOD}

This was a prospective cohort study which was conducted at the Special Care Baby Unit (SCABU) and Intensive Care Unit (ICU) of Dhaka Shishu (Children) Hospital, Dhaka, Bangladesh during the period from July 2012 to December 2014. In total One Hundred and Twenty (120) 0-28 day's old neonates of both sexes possibilities of ROP were finalized as the study population. Data were processed and analyzed using statistical software SPSS 
version 17, EPI info 7. It was a Prospective cohort study. This study was conducted at Special Care Baby Unit (SCABU) and Intensive Care Unit (ICU) of Dhaka Shishu Hospital. Ophthalmoscopic examinations have been performed at Paediatric Ophthalmology Department of National Institute of Ophthalmology, Dhaka during July 2012 to December 2014. Sample size has been estimated with EPCALC 2000 software by assuming differences in the mean in the healthy and disease (having ROP) group with $80 \%$ power and $95 \%$ significant level. Sampling Method was non probability convenient and purposive sampling. A standard questionnaire including cardinal points of the history, examination findings and investigation results prepared by the investigator was used to collect data. The Ethics Review Board of Bangladesh Institute of Child Health approved the protocol of the study. Informed written consent/Finger print was obtained from all the parents or guardians after they were thoroughly briefed about the nature, interest and purpose of the study. Reassurance was given to parents as there was no harmful effect for babies or economic loss.

\section{Inclusion Criteria:}

- Baby's birth weight $\leq 2500 \mathrm{gm}$.

- Babies Born at $<34$ weeks of Gestation.

- Selected preterm babies with a birth weight between $1500 \mathrm{~g}$ and $2500 \mathrm{~g}$ with sickness like need of cardiorespiratory support, prolong oxygen therapy, apnea of prematurity, anemia needing blood transfusion and neonatal sepsis.

\section{Exclusion Criteria:}

- Neonates who had congenital anomalies

- Syndromic manifestations or suspected inborn errors of metabolism.

- Neonates who had congenital eye problems like cataract, glaucoma or corneal opacities.

- Neonates who did not get supplemental oxygen.

Photographs were taken with due permission of the parents. The adequate facilities to manage any risk or adverse condition developed by the participants during the study were ensured. For collecting and displaying data and the findings MS Excel were used.

\section{RESULT}

In our study after third and final screening of ROP we found 38 ROP positive patients which was $31.67 \%$ among total participants and 82 ROP negative patients which was $68.33 \%$ among total 120 study people. In gender distribution of our study we found among all the participants $61.67 \%$ were male whereas $38.33 \%$ were female. So male were dominating in this study. Among 38 ROP (+ve) patients $63.16 \%$ was male and $36.84 \%$ was female. On the other hand, among 82 ROP (-ve) patients
$60.98 \%$ was male and $39.02 \%$ was female. In this study, thirty $(36.59 \%)$ neonates got oxygen up to 72 hours did not developed ROP. Only one $1(2.63 \%)$ ROP (+ve) neonates received oxygen for 73 to 120 hours. Those who received oxygen for duration of 170-218 hours and $>218$ hours developed ROP, RR was 2.01 [1.17-3.48] and 4.67 [2.71$8.03]$ respectively and $(\mathrm{p}<0.05)$. On the other hand, five neonates $(13.16 \%)$ of ROP (+ve) got percentage of oxygen in inhaled air (41-60)\% and this concentration was found statistically significant risk for ROP, RR 3.48 [2.61-4.64] but there was no risk associated with $\mathrm{FiO} 2$ (24-32)\% or 33$40 \%$ in inhaled air. $\mathrm{SpO}_{2}(95-99) \%$ was present in 29 (76.32\%) of ROP (+ve) neonates and $19(23.17 \%)$ in ROP (-ve) neonates. The difference was statistically significant $(p<0.05)$ between the groups and RR 4.8 [2.51-9.28] for saturation of $95-99 \%$. Partial pressure $>150 \mathrm{~mm}$ of $\mathrm{Hg}$ present in 15 (39.47\%) cases of ROP (+ve) neonates and 7 $(8.54 \%)$ in ROP (-ve) neonates. The difference was statistically significant $(\mathrm{p}<0.05)$ between the groups and RR 2.90 [1.83-4.5] for partial pressure $(>150)$ but there was no risk for partial pressure of 70-99 and 100-150 mm of $\mathrm{Hg}$.

Table I: Distribution of study neonates regarding ROP ( $N=120)$

\begin{tabular}{ccc}
\hline ROP & $\mathrm{n}$ & $\%$ \\
\hline ROP (+ve) & 38 & 31.67 \\
ROP (-ve) & 82 & 68.33 \\
\hline
\end{tabular}

Table II: Gender distribution of study neonates ( $N=120)$

\begin{tabular}{|c|c|c|c|c|c|c|}
\hline \multirow{2}{*}{ Gender } & \multicolumn{2}{|c|}{ ROP $(+\mathrm{ve}) ; \mathrm{n}=38$} & \multicolumn{2}{c|}{$\mathrm{ROP}(-\mathrm{ve}) ; \mathrm{n}=82$} & \multicolumn{2}{c|}{ Total $(\mathrm{n}=120)$} \\
\cline { 2 - 7 } & $\mathrm{n}$ & $\%$ & $\mathrm{n}$ & $\%$ & $\mathrm{n}$ & $\%$ \\
\hline Male & 24 & 63.16 & 50 & 60.98 & 74 & 61.67 \\
\hline Female & 14 & 36.84 & 32 & 39.02 & 46 & 38.33 \\
\hline Total & 38 & 100 & 82 & 100 & 120 & 100.00 \\
\hline
\end{tabular}

Table III: Distribution of duration of oxygen inhalation in hours $(n=120)$

\begin{tabular}{|c|c|c|c|c|}
\hline \multirow{2}{*}{ Duration } & ROP (+ve) & ROP (-ve) & RR [95\% Cl] & $P$ value \\
\hline & $(n=38)$ & $(n=82)$ & & \\
\hline $24-72^{*}$ & $0(0 \%)$ & $30(36.59 \%)$ & 0 & 0.0001 \\
\hline $73-120 *$ & $1(2.63 \%)$ & $19(23.17 \%)$ & $0.13[0.01-0.9]$ & 0.005 \\
\hline 121-169* & $4(10.53 \%)$ & $17(20.73 \%)$ & $\begin{array}{c}0.55[0.22- \\
1.39]^{\prime}\end{array}$ & 0.17 \\
\hline $170-2189$ & $8(21.05 \%)$ & $6(7.32 \%)$ & $2.01[1.17-3.48]$ & 0.027 \\
\hline$>2189$ & $25(65.79 \%)$ & $10(12.20 \%)$ & $4.67[2.71-8.03]$ & 0.0001 \\
\hline Total & 38 & 82 & & \\
\hline
\end{tabular}

Table IV: Distribution of percentage of oxygen in the inhaled air (calculated $\mathrm{FiO}_{2}$ )

\begin{tabular}{|c|c|c|c|c|}
\hline $\begin{array}{c}\text { Calculated } \\
\mathrm{FiO}_{2}\end{array}$ & $\begin{array}{c}\text { ROP (+ve) } \\
(\mathrm{n}=38)\end{array}$ & $\begin{array}{c}\text { ROP (-ve) } \\
(\mathbf{n}=82)\end{array}$ & $\begin{array}{c}\mathrm{R} \\
\text { value }\end{array}$ \\
\hline $24-32^{\uparrow}$ & $19(50 \%)$ & $62(75.61 \%)$ & $0.48[0.28-0.80]$ & 0.005 \\
\hline $33-40 \%$ & $14(36.84 \%)$ & $20(24.39 \%)$ & $1.47[0.872 .49]$ & 0.159 \\
\hline $41-60 *$ & $5(13.16 \%)$ & $0(0 \%)$ & $3.48[2.61-4.64]$ & 0.001 \\
\hline Total & 38 & 82 & & \\
\hline
\end{tabular}

* Fisher's exact test; ๆ Chi square test; P value $<0.05$ is significant. 
Table V: Oxygen saturation $\left(\mathrm{SpO}_{2}\right)$ and association with $\mathrm{ROP}$ $(n=120)$

\begin{tabular}{|c|c|c|c|c|}
\hline SpO2 & ROP (+ve) & ROP (-ve) & RR [95\% Cl] & $\begin{array}{c}\text { P } \\
\text { value }\end{array}$ \\
\hline & $(\mathrm{n}=38)$ & $(\mathrm{n}=82)$ & & \\
\hline $85-89 *$ & $1(2.63 \%)$ & $\begin{array}{c}10 \\
(12.20 \%)\end{array}$ & $\begin{array}{c}0.26 \\
{[0.04-1.76]}\end{array}$ & 0.09 \\
\hline $90-949$ & $8(21.05 \%)$ & $\begin{array}{c}53 \\
(64.63 \%)\end{array}$ & $\begin{array}{c}0.25 \\
{[0.12-0.51]}\end{array}$ & 0.001 \\
\hline $95-999$ & $\begin{array}{c}29 \\
(76.32 \%)\end{array}$ & $\begin{array}{c}19 \\
(23.17 \%)\end{array}$ & $4.8[2.51-9.28]$ & 0.001 \\
\hline Total & 38 & 82 & & \\
\hline
\end{tabular}

ПChi square test; *Fisher's exact test; $p$ value $<0.05$ is significant

Table VI: Distribution of Partial pressure of oxygen $\left(\mathrm{PaO}_{2}\right)$ and association with ROP $(n=120)$

\begin{tabular}{|c|c|c|c|c|}
\hline $\mathrm{PaO} 2$ & $\begin{array}{l}\text { ROP } \\
\text { (+ve) }\end{array}$ & $\begin{array}{l}\text { ROP } \\
\text { (-ve) }\end{array}$ & $\begin{array}{c}\mathbf{R R} \\
{[95 \% \mathrm{Cl}]}\end{array}$ & $\begin{array}{c}P \\
\text { value }\end{array}$ \\
\hline$(\mathrm{mm}$ of $\mathrm{Hg})$ & $(n=38)$ & $(n=82)$ & & \\
\hline 70-99* & $2(5.26 \%)$ & $\begin{array}{c}36 \\
(43.90 \%)\end{array}$ & $\begin{array}{c}0.11 \\
{[0.30-0.47]}\end{array}$ & 0.001 \\
\hline 100-150ๆ & $21(55.26 \%)$ & $\begin{array}{c}39 \\
(47.56 \%)\end{array}$ & $\begin{array}{c}1.23 \\
{[0.72-2.09]}\end{array}$ & 0.43 \\
\hline >150ף & $\begin{array}{c}15 \\
(39.47 \%)\end{array}$ & 7 (8.54\%) & $\begin{array}{c}2.90 \\
{[1.83-4.5]}\end{array}$ & 0.001 \\
\hline Total & 38 & 82 & & \\
\hline
\end{tabular}

\section{DISCUSSION}

In this study 120 patients completed the first screening, 38 $(31.1 \%)$ were abnormal and $82(68.3 \%)$ were normal. Sixty two percent were male and $38.3 \%$ were female. Most of the neonates had their first screening examination within a chronological age of 4-6 weeks. Twelve $(10 \%)$ neonates were unable to be present to the ophthalmologist in due time. The failure to attend to the ophthalmologist was probably due to the parent's fatigueability after a long stormy hospital stay or due to long distance of the residence and financial constraints. It has well-known variation in the incidence as well as in associated risk factors among centers and among countries, related to differences in case ascertainment, sampling variability, and aspects of both obstetric and neonatal clinical practice. ${ }^{23}$ Accumulating all the results of screening examinations $18(15 \%)$ neonates could be labeled as having stage 1 ROP and $33(27.5 \%)$ neonates had stage 2 ROP, 21 (17.7\%) infants had $\geq$ stage 3 ROP. The incidence of ROP in this study is similar to studies done in India, Pakistan and Nepal. However, the inclusion criteria differs in some of these studies. ${ }^{24}$ In this study 14 significant factors have been found to be related with the occurrence of ROP on univariate analysis. Those were GA, ELBW, VLBW, clinical septicaemia, culture + ve sepsis, oxygen by head box, mechanical ventilation, oxygen flow $\geq 4$ liter/min, duration of oxygen for 170-218 hours, duration of oxygen $>218$ hours, $\mathrm{FiO}_{2}, \mathrm{SpO}_{2}, \mathrm{PaO}_{2}$, blood volume $>40 \mathrm{ml} / \mathrm{kg}$. Multivariate logistic regression analysis was done including all of these factors. Finally ELBW, Mechanical ventilation, Duration of oxygen $>218$ hours and $\mathrm{SpO}_{2}>95 \%$ was found to be most significant. The role of oxygen therapy as a predictor of ROP has been reported in several other studies. ${ }^{16}$ In the present study multivariate logistic regression analysis found that $\mathrm{SpO}_{2}$ is a major risk factor for ROP. Among the 38 ROP (+ve) neonates 29 (76.32\%) neonates had $\mathrm{SpO}_{2}$ (95-99) \% [RR 4.8 (CI 2.519.28)]. Many studies ${ }^{25}$ have proven the role of hyperoxia or high $\mathrm{SpO}_{2}(>95 \%)$ in the pathogenesis of ROP. Casecontrol study by STOP-ROP multicenter study group ${ }^{19}$ have revealed that infants who developed severe ROP, compare with infants of similar gestation and birth who do not have ROP, have hospital courses characterized by more complex medical problems, prolong oxygen requirements, lower overall arterial oxygenation levels, and more episodes of fluctuating blood oxygen levels with hyperoxia. Other observational studies ${ }^{26}$ have reported the beneficial effects of lower target oxygen saturation levels on the incidence and severity of ROP. A randomized study ${ }^{27}$ reported that a target range of oxygen saturation of 85 to $89 \%$ increased mortality while substantially decreasing severe ROP among survivors as compared with a target range of oxygen saturation of 91 to $95 \% . \mathrm{PaO}_{2}$ values above $80-90 \mathrm{~mm} \mathrm{Hg}$ may be considered hyperoxemiae. ${ }^{28}$ Haurpurg at $e l^{29}$ found that infant exposed to high $\mathrm{PCO}_{2}$, low $\mathrm{P}^{\mathrm{H}}$ and high $\mathrm{PaO}_{2}$ appear to be at increased risk of more severe ROP. In the current study $\mathrm{PaO}_{2}$ was measured intermittently as per advised by consultant neonatologist. It was found that $15(39.47 \%)$ neonates of ROP (+ve) found to have $\mathrm{PaO}_{2}>150 \mathrm{~mm}$ of $\mathrm{Hg}$ and the RR 2.90 [CI 1.83-4.5]. The high $\mathrm{PaO}_{2}$ of this group may be due to blood sample were taken while the neonates on oxygen therapy. When duration of oxygen therapy was compared in the ROP (+ve) and ROP (-ve) group, this difference was significant $(\mathrm{P}<0.05)$. The mean duration of supplemental oxygen in the ROP $(+v e)$ neonates 299 hours and in ROP (-ve) neonates it was 128 hours. Multiple logistic regression analysis using SPSS identified, duration of oxygen as an independent factors which could significantly predict development of ROP $(\mathrm{P}=0001)$. Teioh et $\mathrm{l}^{30}$ found that the duration of exposure to oxygen therapy increase, the risk of development of ROP, in their study the mean duration of oxygen therapy among 36 infants with ROP was 9.4 days. In India, Rekha et $a^{\beta 1}$ reported that duration of oxygen therapy and anemia were independent factors predicting the development of ROP. On the contrary Patil J et $a l^{32}$ in their study did not demonstrate any significant association between ROP and length of time in supplemental oxygen or the mean maximum concentration required. In this study the $\mathrm{FiO}_{2}$ 
was measured indirectly according to Guha $e t a^{33}$ the $\mathrm{FiO}_{2}$ was not measured directly as lack of oxygen analyzer this is the limitation of the study. In the current study five neonates $(13.16 \%)$ of ROP (+ve) got percentage of oxygen in inhaled air (41-60)\% and this concentration was found statistically significant risk for ROP, RR 3.48 [2.61-4.64]. In 1954 a large trial was performed to investigate the risk of supplemental oxygen therapy. The conclusion of this trial was that it was safe to give oxygen to newborn infants as long as the $\mathrm{FiO}_{2}$ was below $40 \% .{ }^{34}$ From this study it has been known that overall ROP incidence is $31.7 \%$, Studies in larger scale and with enough logistic support should be undertaken to know the exact incidence and risk factors in this country. As described by Vision 2020, to reduce the incidence of ROP some strategies like routine fundus examination of premature neonates $<34$ weeks' gestation and /or birth weight $<1500 \mathrm{~g}$, provision of carefully monitored levels of supplemental oxygen and screening by well trained and well equipped ophthalmologist are urgent necessities. ${ }^{3}$

\section{LIMITATIONS OF THE STUDY}

Ideally, screening for ROP should be started during the hospital stay of the neonates. During this study, other than three cases, eye examination could not be arranged during hospital stay. For eye examination the parents needed to visit another hospital which was difficult and troublesome for them. Documented maternal history was not available in some of the cases. Besides these, due to lack of logistic support $\mathrm{FiO}_{2}$ was not measured by oxygen analyzer. On the other hand due to non- availability of apnoea monitor, number of apneic attacks could not be recorded exactly.

\section{CONCLUSION}

This study concluded that there is a significant effect of supplemental oxygen on development of ROP. The practice of providing oxygen and blood transfusion are often lifesaving, a more judicious approach to the use of such therapies may help to reduce the problem of ROP. Inappropriate supplementation of oxygen may not correct hypoxia or may lead to hyperoxia. Both the conditions are injurious to neonatal health. During oxygen therapy, $\mathrm{SpO}_{2}$ value and more precisely the $\mathrm{PaO}_{2}$ value on neonate should be maintained within a target range. The finding of this study should be explored in the future.

\section{REFERENCES}

1. Sola A, Chow L, Rogido M. Retinopathy of prematurity and oxygen therapy: A changing relationship. An Pediatr (Barc) 2005; 62(1): 48-61.

2. Saugstad OD. Oxygen and retinopathy of prematurity. Journal of Perinatology 2006; 26: S46-S50.
3. Gilbert C, Foster A. Childhood blindness in the context of VISION 2020-the right to sight. Bull World Health Organ 2001; 79: 227-32.

4. Bhattacharjee H, Das K, Borah RR, Guha K, Gogate P, Punikayastha S, et al. Causes of childhood blindness in the northeastern states of India. Indian J Ophthalmol 2008; 56: 495-9.

5. Gilbert C. Retinopathy of prematurity: a global perspective of the epidemics, population of babies at risk and implications for control. Early Hum Dev 2008; 84 : 77-82.

6. Gilbert C, Alistair F, Fielder A, Luz G, Graham Q Renato S Patricia V, Andrea Z. Characteristics of infants With Severe Retinopathy of Prematurity in Countries With Low, Moderate, and High Levels of Development: Implications for Screening Programs. Pediatr 2005; 115: e518-e25.

7. Gilbert C. Changing challenges in the control of blindness in children. Eye (Lond) 2007; 21: 1338-43.

8. Phelps DL. Retinopathy of prematurity: an estimate of vision loss in the United States-1979. Pediatrics 1981; 67: 924-25.

9. Gibson DL, Sheps SB, Schechter MT. Retinopathy of prematurity: a new epidemic? Pediatrics 1989; 83: 486-92.

10. Gilbert C. Retinopathy of prematurity: Epidemiology. Comm Eye Health J 1997; 10: 22-24.

11. Courtright $\mathrm{P}$, Hutchinson AK, Lewallen S. Visual impairment in children in middle- and lower-income countries. Arch Dis Child 2011; 96:1129-34.

12. Gilbert C, Rahi J, Eckstein M, et al. Retinopathy of prematurity in middle-income countries. Lancet 1997; 350: $12-14$.

13. Ugurbas SC, Gulcan H, Canan H, Ankarali H, Torer G, Akova YA. Comparison of UK and US screening criteria for detection of retinopathy of prematurity in a developing nation. Journal of AAPOS 2010; 14: 506-10.

14. Anand V, Mangat DR, Tiakumzuk S, Narang A, Gupta A. Retinopahty of prematurity in Asian Indian Babies weighing greater than 1250 grams at birth: Ten year data from a tertiary care center in a developing country. Indian J Ophthalmol 2007; 55: 331-36.

15. Chen Y, Li X. Characteristics of severe retinopathy of prematurity in patients in China: a repeat of the first epidemic? Br J Ophthalmol 2006; 90: 268-71.

16. Mc Clom JR, Fleck BW. Retinopathy of prematurity: causation. Semin Neonatol 2000; 6: 453-60.

17. Sola A, Rogido MR, Deulofeut R. Oxygen as a neonatal health hazard: call for détente in clinical practice. Acta Paediatrica 2007; 96:801-12.

18. McGregor ML, Bremer DL, Cole C, McClead RE, Phelps DL, Fellows RR. HOPE-ROP Multicenter Group. High Oxygen Percentage in Retinopathy of Prematurity study. Retinopathy of Prematurity outcome in infants with prethreshold retinopathy of prematurity and oxygen saturation $>94 \%$ in room air: the high oxygen percentage in retinopathy of prematurity study. Pediatrcs 2002; 110: 540-44.

19. The STOP-ROP multicenter study Group. Supplemental Therapeutic oxygen for Prethreshold Retinopathy of Prematurity (STOP-ROP), a randomized controlled trial. I: primary outcomes. Pediatrics 2000; 10: 295-10. 
20. Akter S, Shirin M, Hossain MM. Retinopathy of prematurity- Are we prepared to Face the Third Epidemic? Bangladesh J Child Health 2006; 30: 25-28.

21. Ahmed AS, Muslima H, Anwar KS, Khan NZ, Chowdhury MA, Saha SK, Darmstadt GL. Retinopathy of prematurity in Bangladeshi neonate. J Trop Pediatr 2008; 54: 333-9.

22. Muhit MA, Shah SP, Gilbert CE, Foster A. Causes of severe visual impairment and blindness in Bangladesh: a study of 1935 children. Br J Ophthalmol 2007; 91: 10004.

23. Manjoni P, Farina D, Maestri A, Giovannozzi C, Leonessa ML, Arisio R et al. Mode of delivery and threshold retinopathy of prematurity in preterm ELBW neonates. Acta Pediatrica 2007; 96: 221-26.

24. Chaudhari S, Patwardhan V, vaidya U, Kadam s, Kamat A. Retinopathy of prematurity in a tertiary care centreIncidence, risk factors and outcome. Indian Pediatr 2009; 46: 219-24.

25. Wheatley CM, Dickinson JL, Mackey DA, Craig JE, Sale MM. Retinopathy of prematurity: recent advances in our understanding. Arc Dis Child Fetal Neonate Ed. 2002; 87 F78-82.

26. Wright KW, Sami D, Thompson L, Ramanathan R, Joseph R. A Physiologic reduced oxygen protocol decrease the incidence of threshold retinopathy of prematurity. Trans Am Ophthalmol Soc 2006; 104: 78-84

27. SUPPORT study Group of the the Eunice Kennedy Shriver NICHD Neonatal Research Network, Carlo WA,
Finer NN, Walsh MC, Rich W, Gantz MG. Target ranges of oxygen saturation in extremely preterm infants. N Engl J Med J (Engl) 2010; 362: 1959-69.

28. Flyn JT, Bancalari E, Snyder ES, Goldberg RN, Feuer W, Cassady J. A cohort study of transcutaneous oxygen tension and the incidence and severity of retinopathy of prematurity. N Engl J Med 1992; 326: 1050-4.

29. Hauspurg AK, Allred EN, VAnderveen DK, Chen M, Bednarek FJ, Cole $\mathrm{C}$ at el. Blood gases and retinopathy of prematurity: the ELGAN study. Neonatology 2011; 99: 104-11.

30. Teioh SL, Boo NY, ONG LC, Nyein MK, Lye MS. Duration of oxygen therapy and exchange transfusion as risk factors associated with retinopathy of prematurity in very low birth weight infants. Eye 1995; 9: 733-37.

31. Rekha S, Battu RR. Retinopathy of prematurity: Incidence and risk factors. Indian Pediatr 1996; 33: 999-03.

32. Patil J, Deodhar J, Wagh S, Pandit AN. High risk factors for development of retinopathy of prematurity. Indian Pediatr 1997; 34: 1024-27.

33. Guha DK, Guha R, Srivastava RD, Editors. Manual of Neonatal critical care medicine 1st ed. New Delhi: Jaypee Brothers Medical Publisher; 2006.

34. Kinsey VE, Jacobus JT, Hemphill F. Retrolental fibroplasia: Cooperative study of retrolental fibroplasias and the use of oxygen. Archives of Pediatrics and Adolescent Medicine 1956; 92(4): 395.

$$
\begin{aligned}
& \text { Source of Support: None Declared } \\
& \text { Conflict of Interest: None Declared }
\end{aligned}
$$

Policy for Articles with Open Access:

Authors who publish with MedPulse International Journal of Pediatrics (Print ISSN: 2579-0897) (Online ISSN: 2636-4662) agree to the following terms: Authors retain copyright and grant the journal right of first publication with the work simultaneously licensed under a Creative Commons Attribution License that allows others to share the work with an acknowledgement of the work's authorship and initial publication in this journal.

Authors are permitted and encouraged to post links to their work online (e.g., in institutional repositories or on their website) prior to and during the submission process, as it can lead to productive exchanges, as well as earlier and greater citation of published work. 